\title{
Population Projection Revisions and Their Impact on Economic Growth - The Case of Malta
}

\author{
Aaron G Grech ${ }^{1, *} \&$ Ian Borg ${ }^{1}$ \\ ${ }^{1}$ Economics Division, Central Bank of Malta, Valletta, Malta \\ *Corresponding author: Central Bank of Malta, Valletta, Malta. E-mail: \\ grechga@centralbankmalta.org
}

Received: August 17, 2019 Accepted: September 14, 2019 Published: September 25, 2019

doi: 10.5296/rae.v11i3.15285 URL: https://doi.org/10.5296/rae.v11i3.15285

\begin{abstract}
Typically, in short-term economic forecasts, population projections, and their related impact on the availability of labour, tend to be the most stable component. The scope of this paper is to show how in the case of Malta, the European Union's smallest economy, migration flows have led to substantial revisions in population projections. Using the standard production function approach to estimate potential output growth, these revisions change very substantially expectations of economic expansion. Revisions in population projections are, in fact, estimated to have boosted Malta's potential output growth in future years by as much as half a percentage point. While potential output is seen as a fairly stable variable for medium and large economies, it is more of a fluid concept for small open economies that are subject to large migration flows.
\end{abstract}

Keywords: Migration, Population projections, Economic growth, Potential output

JEL Classification: J11, E32 


\section{Introduction}

Despite being the smallest euro area member state and having considerable trade with the rest of the monetary union, Malta's economy has grown very rapidly since the financial crisis. As at end 2017, Malta's real GDP was, in fact, 46\% higher than it had been in 2008, in stark contrast with the $6 \%$ expansion observed in the rest of the euro area. This strong expansion coincided with a period of considerable inward migration towards Malta, particularly of young Europeans. To a large extent, this inflow was unanticipated, with population projections made at the time indicating the possibility of flows in the other direction.

Population projections play a significant role in determining estimates of potential output growth. The latter has become an increasingly important concept for member states of the European Union (EU). For instance, it is a key operational surveillance tool utilised by the European Commission, especially in the context of the provisions of the Stability and Growth pact (see Havik et al, 2014). In large economies, population projections tend to be relatively stable as they are mainly determined by assumptions on birth rates and on life expectancy. Migration flows can affect large economies, but not to the extent that observed in small economies. In this respect, population projection revisions can lead to very significant changes in the medium-term growth prospects of the smaller member states of the EU.

The aim of this paper is to document how large these changes can be, even on seemingly stable concepts such as potential output. The next section sets out the extent of revisions in population data for Malta, and their subsequent impact on population projections. This is followed by an explanation of the production function approach adopted to estimate potential output growth for the Maltese economy, and how the recent revisions in population projections lead to a significant upward rise in prospective medium-term economic growth.

This study contributes to the literature as there has been very little research on the impact of migration on small economies, particularly where these flows are due to them being part of an economic and monetary union. For instance, Barrell, FitzGerald and Riley (2010) and D'Auria, Mc Morow and Pichelmann (2008) ignore the Maltese case and instead focus on the larger countries which acceded to the EU at the same time as Malta. More recently the literature on the topic has focused on the fact that the economic downturn in euro area periphery countries resulted in some significant reversals of migration trends, with the most-affected countries, like Spain and Greece, shifting from positive inward migration to negative flows (Fertig and Kahanec, 2015).

By contrast this article will look at the alternative case where economic prosperity attracts large inflows. Grech (2017) shows the foreign workforce in Malta is heterogeneous in terms of occupations undertaken. EU-born workers are twice as likely as a Maltese-born worker to be in a managerial role, while the probability a third-country national is employed in an elementary occupation are four and a half times that for the average Maltese. Thus, foreign workers in Malta are employed at either end of the labour market - the higher end where skills are scarce and the lower end where jobs have become unattractive for Maltese workers. 


\section{Data and methodology}

National statistics offices usually focus their limited resources on gathering information on the past and recent periods. The only exception is in the area of demography, where there is a longstanding tradition that population estimates are accompanied with population projections. It is important to note that projections differ from forecasts in that they are "a conditional calculation showing what the future population would be if a particular set of assumptions were to hold true" (George et al, 2004). On the other hand, a forecast represents a specific judgement on the validity of the underlying data and assumptions, rather than simply a scenario. In fact, it has become quite common for national statistics offices to present a set of population projections encompassing an array of assumptions on the major determinants, such as the fertility rate, life expectancy and migration. At a time when there have been major fluctuations in important demographic determinants, namely unexpected migration flows and improvements in life expectancy, population projections have tended to influence the appropriateness of policy stances.

Since joining the EU, population projections for Malta have been prepared by Eurostat, in consultation with Malta's National Statistics Office (NSO).(note 1) The first set of projections, published in 2005 had predicted that by 2050 Malta's population would reach 508,000, constituting the fourth largest increase in the EU. The latest set of projections, EUROPOP2015, which was published in 2016 suggests a slight upward revision to 513,000.(note 2) However over this decade, population projections for Malta have fluctuated significantly. For instance, the EUROPOP-2010 projection had implied a 427,000 population for 2050 , or $17 \%$ less than the latest projection. This had mainly reflected an assumption of strong outward migration till 2015, followed by very small inflows of migrants thereafter.

This assumption turned out to be significantly incorrect by subsequent events. Eurostat (2017), in fact, noted that in 2015, relative to the size of the resident population, Malta had the secondhighest rate of immigration (30 immigrants per 1000 persons), six times the EU average.(note 3) Grech (2017) documents the significant influx of workers from neighbouring economies, such as Italy, such that the share of foreign workers in Malta's labour force grew from under $2 \%$ at the time of accession to over $10 \%$ in just a decade. Administrative data from Malta's national employment register indicate that employed foreign nationals at the end of 2017 amounted to over 44,500 persons, up from almost 4,000 in 2002.

More than two-thirds of this influx was from other EU member states. Back in 2002, British, Italian and Germans were the top three EU nationalities, in that order, amongst EU workers in Malta, accounting for $77 \%$ of this group. There were nearly three times as many British workers in Malta than there were Italians. By 2017 the number of Italian workers in Malta had risen to more than one and a half times the amount of British, even though the latter had risen by more than six times their level in 2002. While the amount of Germans was also six times higher than in 2002, they were no longer the third-largest EU worker community in Malta, but the seventh largest, having been overtaken by the Bulgarians, Romanians, Hungarians and Swedes. Thus while in 2002, UK, Italian and German nationals constituted $77 \%$ of all EU workers in Malta, by 2017 they amounted to less than half of the total. While greater diversity in EU source 
countries started with the accession of Malta to the single market, it became much more accentuated with the onset of the financial crisis. While in 2007, the number of workers from Portugal, Ireland, Italy, Greece, Spain and Cyprus was about 550, a decade after it had risen to nearly 10,500 .

Malta's important role in the flows of migration into the EU is well-documented (Mainwaring, 2014 and Borg-Barthet and Lyons, 2016). However, while on a per capita basis, Eurostat data show Malta features as the country facing the fourth-highest number of asylum applications in the EU, over time it appears that the bulk of the increase in migration to Malta was coming from neighbouring EU countries. While Third Country Nationals working in Malta accounted for $54 \%$ of all foreign workers at the time of EU accession, by 2017 their share had fallen to $31 \%$. For instance, since 2012 the number of Third Country Nationals working in Malta has risen nearly 8,500, which is less than the increase observed from Italy, the UK and Germany.

This dramatic shift in the importance of migration from EU countries caught Malta's statistical office by surprise. Prior to the recent acceleration in migration from neighbouring EU states, most resources were expended to capture the extent of non-EU migration. Grech (2017) in fact noted a significant discrepancy between the estimates of EU workers found in Malta's Labour Force Survey and the figures shown in the national employment register. In early 2018, the NSO published a significant benchmark revision in Malta's population statistics, reflecting methodological improvements in the compilation of migration flows data for EU and regular Third Country Nationals migrants for the period 2012 to 2016 (National Statistics Office, 2018). This confirmed that the population estimates on which population projections had been based significantly under-estimated the number of working age foreigners residing in Malta.

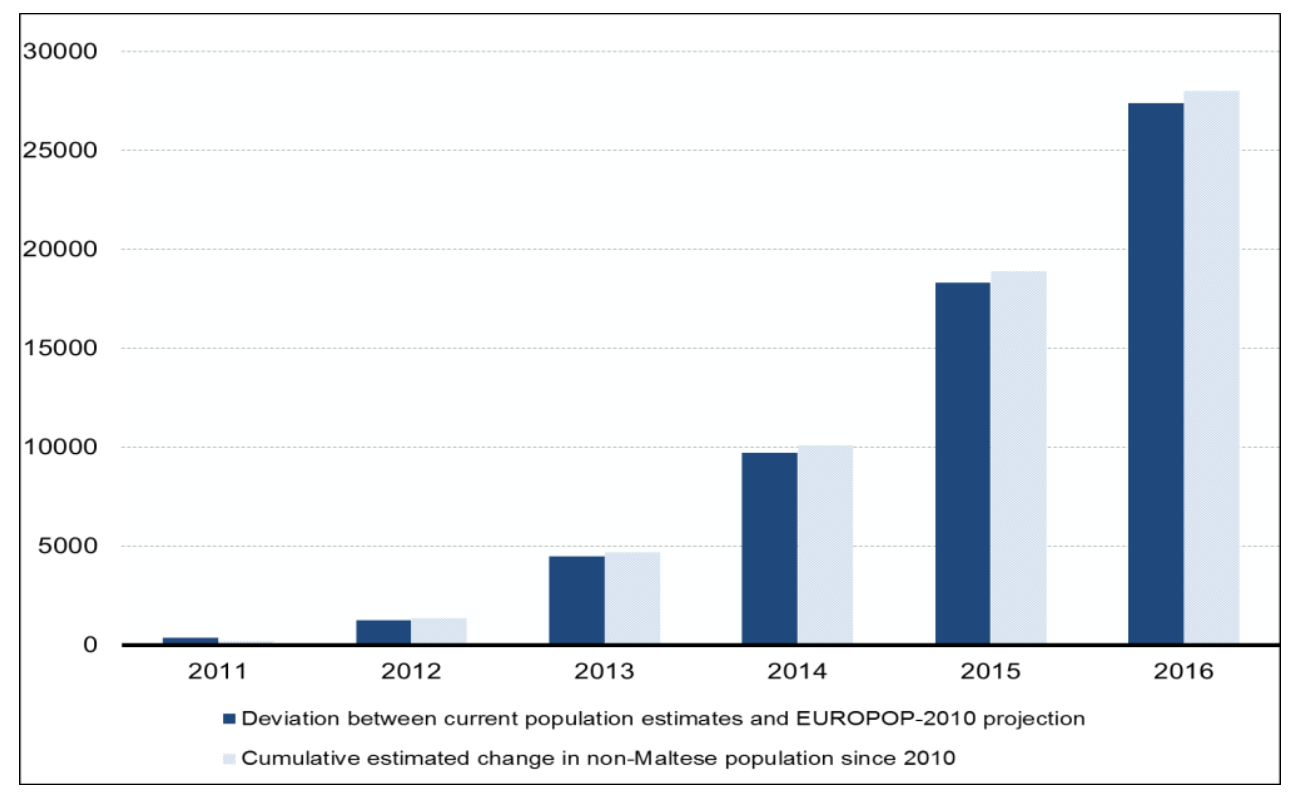

Figure 1. Source of Deviation of Current Population Estimates from EUROPOP-2010 Projections (Number of persons).

Source: Author's calculations using Eurostat and NSO Demographic Review data 


\section{MInstitute Macrothink $_{\text {Int }}$}

Figure 1 shows that by 2016, the EUROPOP-2010 projection was off the mark by nearly 27,400 persons when compared to the current population estimate for that year, constituting an underestimation of $6.5 \%$. This difference mirrors the growth observed in the non-Maltese population over that time. The two subsequent sets of EUROPOP projections reversed the short-term assumption of net outward migration, such that the latest set of projections assumes an average net immigration of nearly 2,600 each year till 2025 .

Such abrupt reversals in assumptions used in population projections are not uncommon, even for larger countries. For instance, Office for National Statistics (2016) documents how UK projections made in the mid-1950s failed to foresee the 1960s baby boom, producing an estimate for 1995 that was 5 million below the actual figure. By contrast the projections made in the 1960 s projected that the spike in fertility would continue, leading to a projection for 2001 that proved to be 16 million over the actual estimate for that year.

In the case of small countries, changes in assumptions can have very dramatic implications. EUROPOP-2010 showed Luxembourg's population at 0.6 million in 2030. EUROPOP-2015 now indicates that this level will be reached before 2020, and that by 2030 it will be nearly a third higher than envisaged in the projections made five years earlier.

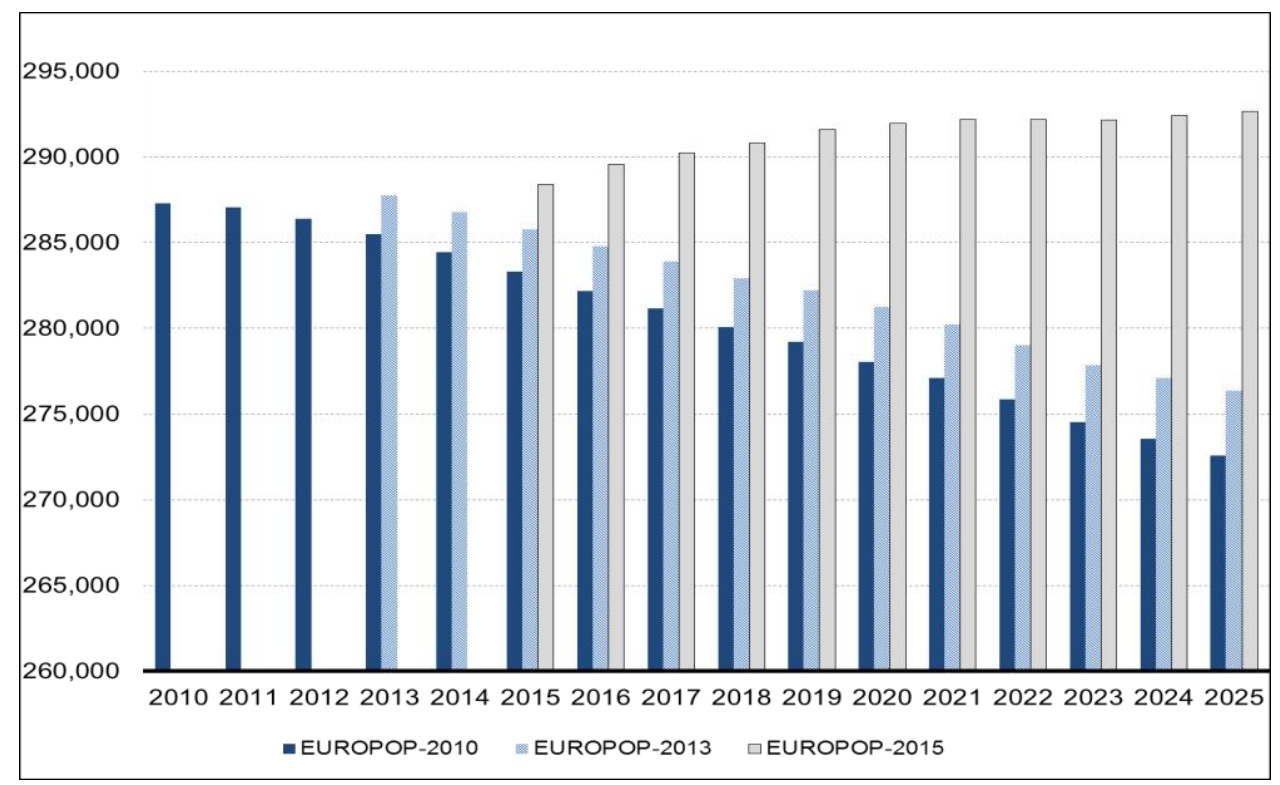

Figure 2. Projected Working Age Population (Number of persons)

Source: Eurostat and NSO

Returning to the Maltese population case, Figure 2 shows the projected working age population (15-64) for the period 2010 to 2025 implied by the three most recent set of EUROPOP projections. Both EUROPOP-2010 and EUROPOP-2013 had shown a declining path for the potential labour supply. By 2016, EUROPOP-2010 had implied a decline of 5,140, or 1.8\%, in 


\section{MInstitute Macrothink $_{\text {Int }}$}

Malta's working age population, while EUROPOP-2013 showed a 2,941, or 1\%, fall. In actual fact, the working age population grew by 2,464 , or $0.9 \%$, between 2010 and 2016 . EUROPOP2015, taking account of this trend, shows a slightly rising profile for this variable, with an implied growth of 3,089 persons, or $1.1 \%$, by 2025. Compared with EUROPOP-2010, the working age population in 2025 is now expected to be nearly 20,100 persons higher, or $7.4 \%$ above the projection made five years earlier.

While this upward revision represents a break from the previous rounds of projections, at $0.9 \%$, the projected annual average rate of growth for the next decade is well below the $1.3 \%$ annual average seen over the last ten years. It is important to note that the EUROPOP-2015 projection was finalised before the benchmark revision in migration flows was published in 2018. In fact, EUROPOP-2015 is already underestimating the working age population in the second year of the projection, by nearly 18,400 persons or $6.0 \%$. Net migration in 2016 was 8,748, or two and a half times the EUROPOP-2015 assumption. Nevertheless, while migration in recent years was quite significant, the EUROPOP-2015 migration assumption compares well with flows seen over the medium term (see Figure 3).

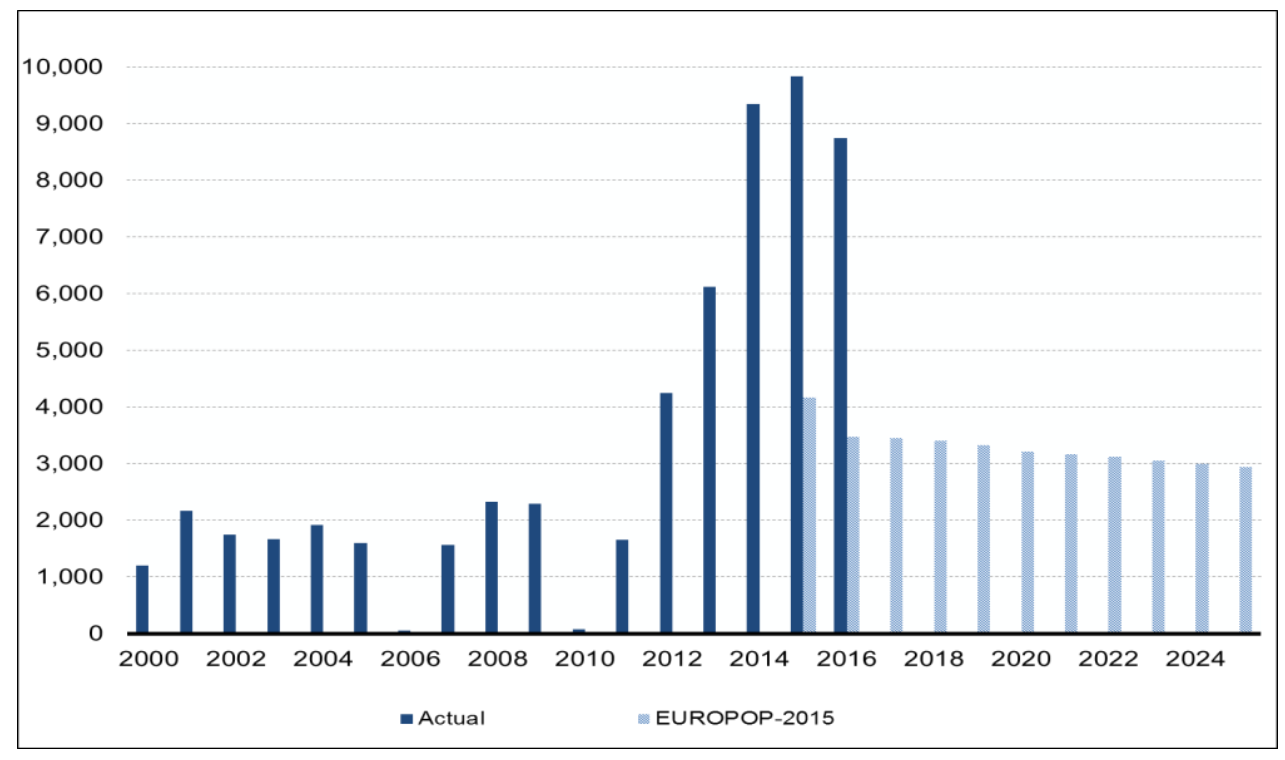

Figure 3. Net migration: Actual and Projected (Number of persons)

Source: Eurostat

Domestic output essentially depends on three main factor inputs, namely, capital, labour, and total factor productivity. Capital stock is a function of investment flows, while total factor productivity refers to the portion of output unexplained by changes in the amount of labour and capital. The labour component is a function of the working age population, hours worked, the participation rate, and a measure of structural employment. Population projections are therefore crucial to the estimation of both historical and future developments in supply, and hence, revised population projections have a direct impact on this estimate. 


\section{Mll Macrothink}

The approach taken to compute potential output is in line with that adopted by the European Commission and utilised for studies relating to the Maltese economy (see Havik et al, 2014; Micallef and Grech, 2014). This involves the use of a constant-returns-to-scale Cobb-Douglas production function.

$$
\mathrm{Y}_{\mathrm{t}}=\mathrm{TFP}_{\mathrm{t}} * \mathrm{~K}_{\mathrm{t}}^{\alpha} * \mathrm{~L}_{\mathrm{t}}^{1-\alpha}
$$

where Yt denotes output at time $\mathrm{t}$, Lt the labour input, Kt the capital stock and TFPt the total factor productivity. TFP is estimated by applying a Hodrick Prescott filter on the Solow residual, using the standard smoothing parameter of 1600 for quarterly data. The Solow residual is, in turn, estimated as that part of economic growth that cannot be explained through growth in the capital stock or in the labour supply utilising fixed coefficients for the two factors of production. The coefficient $\alpha$ is set as 0.42 , based on the share of compensation of employees in gross value added adjusted for the proportion of the labour force that consists of self-employed. The stock of capital is calculated using the perpetual inventory method. Housing investment is excluded from the measurement of the capital stock. The capital stock thus includes both public investment and non-housing investment by the private sector.

The labour input, in turn, is determined as:

$$
\mathrm{L}_{\mathrm{t}}=\mathrm{WAP}_{\mathrm{t}} * \mathrm{PR}_{\mathrm{t}} *\left(1-\mathrm{UNR}_{\mathrm{t}}\right) * \mathrm{HRS}_{\mathrm{t}}
$$

where WAPt denotes the working-age population derived from population projections, PRt the trend participation rate, UNRt the NAIRU and HRSt the trend hours worked. To help derive potential labour utilisation, the trend participation rate and hours worked are obtained using a Hodrick Prescott filter (with standard lambda for annual data). The NAIRU is computed from a multivariate filter, which is based on well-established relationships in economic theory, such as the Phillips Curve and Okun's Law (in line with Benes et al, 2010).

Before discussing the results derived from this approach, it is important to point out the limitations one faces when trying to estimate potential output for a small open economy such as Malta. Grech (2013) points out that the standard empirical approaches "were conceived for large economies with relatively stable macroeconomic series". Structural methods, such as an aggregate production function, depend on high quality data on factors of production, which tend to be less available for small economies. The application of statistical filters to derive estimates of TFP and the NAIRU also raises issues, as these filters tend to perform badly in the presence of pronounced trends, large fluctuations and structural breaks. Consequently, estimates of potential output for small economies need to be interpreted with caution, even more so than those for larger economies. The next section, in fact, will show how revisions in assumptions can shift assessments of potential output very significantly.

\section{Results}

The forecast of potential output is based on a number of key assumptions. TFP is assumed to grow by the average rate observed over the last thirty years - this marks a slowdown from the high rates of growth seen in more recent years. This assumption is taken in light of studies 
(such as Rapa, 2017) which have estimated that a significant part of recent expansion in capacity reflected one-off factors such as energy reforms. The transition to slower TFP growth is assumed to be gradual in the first five years of the projection, and after that TFP expands by the average annual rate seen over the past thirty years (i.e. close to $1.5 \%$ ).

Malta's capital stock has tended to grow less rapidly than its output, resulting in a falling capital-output ratio. To a large extent this reflects the transition of the Maltese economy towards more services-oriented activities that rely more on labour and human capital, rather than machinery and physical equipment. For the purposes of this forecast we assume that the investment to GDP ratio stays constant during the projection horizon.

The labour participation rate is assumed to rise gradually to $75 \%$ by 2025 , in line with the Maltese government's EU2020 target. This increase in participation is partly going to be in part-time employment, reflecting an ever-rising share of women joining the workforce. As a result, we extend forwards the trend decline in average hours worked in line with our projection of rising part-time employment. The latter is set to equal the share observed in the EU by the end of the horizon period. Malta's structural unemployment rate is held constant during the forecast horizon. We believe that the latter has declined considerably in recent years due to structural changes in the labour market and changes in the benefit system, both of which are unlikely to generate any further drops in unemployment.

The impact that the revisions in population described in section 2 could imply on Malta's potential output growth over the period 2010-2025 is estimated by applying the different working age population projections corresponding respectively to the EUROPOP-2010, 2013, and 2015 vintages. EUROPOP-2015 includes three scenarios: low migration, baseline projections and high migration. In the first part of this section we will use the baseline projections, providing some sensitivity with the different scenarios later on. All other variables, excluding the working age population, are kept constant across the three estimations in order to isolate the impact of working age population projection vintages.

Figure 4 shows the average impact of the different vintages of population projections on potential output growth, in three different periods.(note 4) In each case, working age population projections were revised upward, and hence each new projection vintage implies an upward revision to potential output growth. When comparing the EUROPOP-2013 projection with EUROPOP-2010, the largest positive impact occurred in the period 2010-2015, primarily driven by strong upward revisions in the working age population estimates of 2012 and 2013. During this period, the impact of the revised projections stood on average at around 0.09 percentage point. Going forward however, the impact of EUROPOP-2013 working age projections was marginal and at around 0.03 percentage point on average, for both the 20162020 and 2021-2025 periods. 


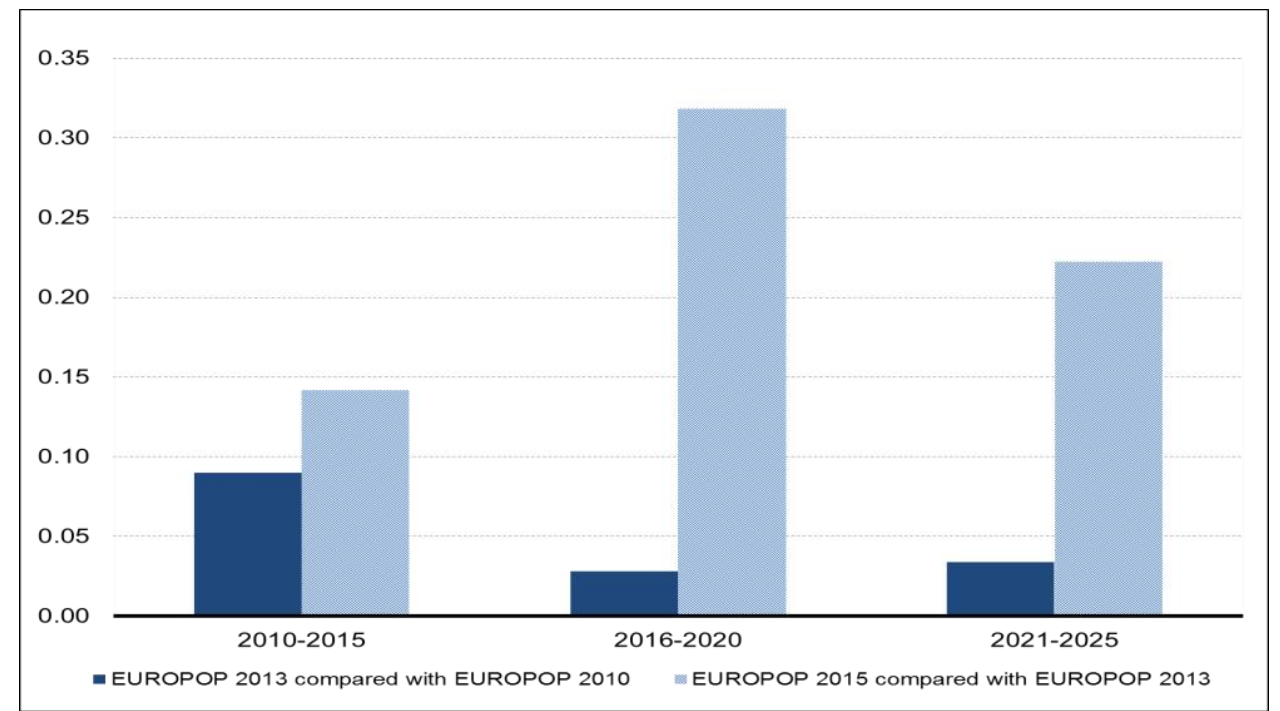

Figure 4. Impact of Revised Projections on Potential Output (percentage point deviation in annual average growth for each period)

Source: Author's calculations

The largest impact on potential output growth occurred with the release of EUROPOP-2015, which revised upwards substantially net migrant flows. On average, the impact for the period 2010-2015 stands at around 0.14 percentage point, driven in large part by a significant acceleration in net migrant flows during 2015. The peak impact is attained for the period 20162020, which implies an upward revision in potential output growth of around 0.32 percentage point. With regard to the medium-term impact of the latest population projections, this stands at around 0.22 percentage point for the period 2021-2025.

\section{Discussion}

EUROPOP-2015 includes three migrant scenarios in order to cater for the fact that net migrant flow projections have become the main source of error in population projections. Chart 5 plots the impact on potential output growth according to different scenarios of migrant flows, compared to EUROPOP 2013. The potential output impact of the low migrant scenario is quite small, peaking at around an average of $0.13 \%$ in the period 2016-2020, which is less than half the estimated impact derived from the baseline scenario. Moreover, the high migrant scenario peak impact in the period 2016-2020 averages at around 0.50\%, while for the period 20212025 the potential output growth impact stands at an average of around $0.39 \%$.(note 5) 


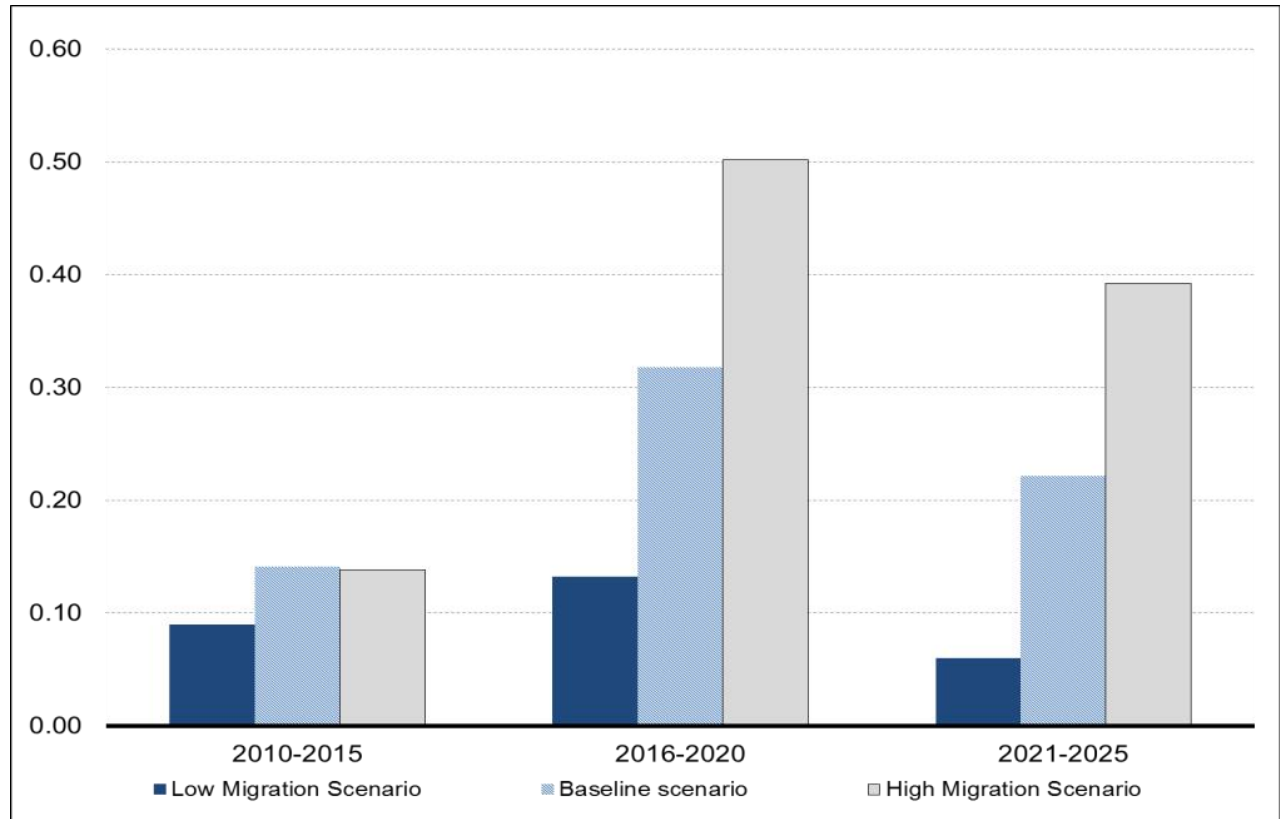

Figure 5. Different Migration Scenarios: EUROPOP 2015 (Percentage point deviation in average annual growth for each period)

Source: Author's calculations

Previous studies (Grech and Micallef, 2015; Micallef and Ellul, 2017) have utilised EUROPOP-2013 projections to estimate potential output growth. These studies projected on average medium-term potential output growth of around 3.25\% for the period 2021-2025, which is $1 \%$ less than the period 2016-2020. The estimated impacts shown in charts 4 and 5 imply that potential output growth for the period 2016-2020 should be revised up to a range of between $4.4 \%$ to $4.8 \%$, while for the period 2021-2025 should be closer to a range of between $3.3 \%$ to $3.6 \%$.

The assumption that the investment-to-GDP ratio is constant may be too restrictive, as the increase in working age population due to migration would reduce the return to capital, which would induce further investment. Moreover, the increase in population is likely to increase the investment needed to sustain a rise in demand for services such as health, education, and infrastructure. Compared to the 2013 working age population projections, the net migrant scenario assumed in the 2015 baseline induces a 3.0\% higher labour force. If we assume a similar rise in investment of $3.0 \%$, it would result in even higher equilibrium potential output. In the 2016-2020 period potential output would be around 0.5 percentage points higher than the 2013 potential output, higher than the 0.3 percentage points if we assume a constant investment-GDP ratio. In the period 2021-2025 potential output would be around 0.4 percentage points higher, compared to the 0.2 percentage points when assuming a constant investment-to-GDP ratio.

On the other hand, the impact of the increase in labour force is unlikely to have a neutral effect 
on productivity. Foreign workers bring about new skills, which would have a positive impact on TFP. On the other hand, Grech (2017) has shown that the share of lower skilled foreign workers has increased when compared with higher skilled workers, which would in turn have a negative impact on TFP. Hence, we consider two scenarios (low and high) whereby we relax the TFP growth assumed for this paper.

For the lower-TFP scenario, we assume a growth rate of TFP of around 1.3\%, equal to the average TFP growth experienced over the period 1995-2016. If we apply this assumption to the 2015 baseline scenario and compare it with the EUROPOP-2013 working age population, the impact on potential output for the period 2016-2020 remains similar to that reported in chart 4, that is a positive impact of around 0.3 percentage points. However, for the period 2021-2025, the deviation between EUROPOP-2013 and EUROPOP-2015 potential output is broadly neutral, when considering a lower-TFP growth scenario. This implies that the impact of higher net migrant flows on potential output is largely temporary, as the positive impact emanating from higher net migrant flows is largely offset by lower TFP.

On the other hand, if we assume that new skills brought about by foreign workers would have a positive impact on productivity, the impact on potential output would be permanent and larger than that reported in chart 4. For the higher-TFP scenario we assume TFP growth of around $1.6 \%$, equal to the average TFP growth experienced over the period 2013-2016. This period coincides with the sharp rise in net migrant flows. This higher-TFP scenario would add a further 0.1 percentage points to potential output for the period 2016-2020. In other words, the deviation between EUROPOP-2013 and EUROPOP-2015 baseline projections would reach 0.4 percentage points. Conversely, the long-run impact of the higher growth in TFP is rather minimal, as we assume that productivity gains are likely to occur in the near future.

Note, however, that these estimates are based on the assumption that migrant workers, which constitute the bulk of the upward revision implied in the EUROPOP-2015 projection, have the same productivity and employment patterns as locals. Grech (2017), on the other hand suggests that migrant workers tend to be more concentrated in the managerial and professional category and work in high-valued services. This may mean that the estimates presented here underestimate the potential impact of higher numbers of foreign workers. Furthermore, as was already hinted earlier, the EUROPOP-2015 projection is based on relatively conservative assumptions on future migration when compared to the revised data on recent migration flows published by the NSO.

While the rise in potential output growth is welcome, the increase in population growth poses a number of challenges for the Maltese economy. Firstly, the increase in population is likely to add additional stress on infrastructure, which could negatively affect potential output growth in the absence of adequate investment. Furthermore the steep rise in the share of non-Maltese population in the labour supply might add cyclicality in potential output, as foreign workers may be more prone to leave the country in the face of negative economic shocks.(note 6) These two factors suggest the importance for considerable investment in infrastructure over the coming years, together with additional efforts to further upskill the local workforce to enable it to better accommodate the needs of a Maltese economy diversifying its activity into new 
sectors. It will also be important to maintain the flexibility achieved in recent years in the labour market, possibly with policies targeted at increasing the employment rates of older workers. That said, the increased degree of reliance on migrant workers also implies that firms will need to get used to higher rates of labour turnover, which could create challenges to maintain and improve productivity. Outlays on training and organisational structures will need to be strengthened.

\section{Conclusion}

Population projections are surrounded by considerable uncertainty since these depend on a number of assumptions to hold true for a considerably long period of time into the future. As a result, these tend to be revised significantly across different projection vintages. For the case of Malta, whereas in both EUROPOP-2010 and EUROPOP-2013 Malta's working age population was expected to fall due to the effects of an ageing population, the latest EUROPOP2015 projections outline a scenario whereby this is expected to continue growing at steady rates over the next seven years. This implies a further boost to Malta's potential output growth of between $0.3 \%$ to $0.5 \%$ for the period $2016-2020$, and $0.2 \%$ to $0.4 \%$ for the period $2021-2025$.

This finding has particular macroeconomic implications. It suggests that when a country is a member of a monetary and economic union with freedom of movement of labour, even a supposedly stable concept like potential output can prove to be quite volatile. This has important implications for policy surveillance purposes. It is well known that small open economies are more susceptible to changes in foreign demand conditions and foreign direct investment flows. The experience of Malta over the last decade suggests that, to an extent, this is also true for the availability of labour and for estimates of economic capacity. This points towards the importance of not focusing too much on point forecasts and instead developing policies that are robust to different economic scenarios.

\section{References}

Barrell, R., FitzGerald, J., \& Riley, R. (2010). EU enlargement and migration: assessing the macroeconomic impacts. Journal of Common Market Studies, 48(2), 373-395. https://doi.org/10.1111/j.1468-5965.2009.02056.x

Benes, J., Clinton, K., Garcia-Saltos, R., Johnson, M., Laxton, D., Manchev, P., \& Matheson, T. (2010). Estimating potential output with a multivariate filter. IMF Working Paper WP/10/285, International Monetary Fund.

Borg-Barthet, J., \& Lyons, C. (2016). The European Union migration crisis. Edinburgh Law Review, 20(2), 230-255. https://doi.org/10.3366/elr.2016.0346

D’Auria, F., McMorrow, K., \& Pichelmann, K. (2008). Economic impact of migration flows following the 2004 EU enlargement process: a model analysis. European Economy, Economic Papers 349, European Commission. 


\section{Macrothink}

Eurostat. (2017). Summary methodology of the 2015-based population projections. Technical note.

Fertig, M., \& Kahanec, M. (2015). Projections of potential flows to the enlarging EU from Ukraine, Croatia and other Eastern neighbours. IZA Journal of Migration, 4(6). https://doi.org/10.1186/s40176-015-0029-8

George, M. V., Smith S. K., Swanson D. A., \& Tayman, J. (2004). Population Projections. In J. S. Siegel, \& D. A. Swanson (Eds.), The Methods and Materials of Demography (pp. 561602). Washington DC: US Census Bureau.

Grech, A. G. (2013). Adapting the Hodrick-Prescott filter for very small open economies. International Journal of Economics and Finance, 5(8), 39-53. https://doi.org/10.5539/ijef.v5n8p39

Grech, A. G. (2017). Did Malta's accession to the EU raise its potential output? A focus on the foreign workforce. Journal of Economic Integration, 32(4), 873-890. https://doi.org/10.11130/jei.2017.32.4.873

Grech, A. G., \& Micallef, B. (2015). Assessing the supply side of the Maltese economy using a production function approach. Xjenza, 3(1), 57-63. https://doi.org/10.7423/XJENZA.2015.1.08

Havik, K., Mc Morrow, K., Orlandi, F., Planas, C., Raciborski, R., Roger, W., Rossi, A., ThumThysen, A., \& Vandermeulen, V. (2014). The production function methodology for calculating potential growth rates and output gaps. Economic Papers 535. European Commission.

Mainwaring, C. (2014). Small states and nonmaterial power: Creating crises and shaping migration policies in Malta, Cyprus and the European Union. Journal of Immigration and Refugee Studies, 12(2), 103-122. https://doi.org/10.1080/15562948.2014.909076

Micallef, B., \& Ellul, R. (2017). Medium-term Estimates of Potential Output Growth in Malta. In A. G. Grech, \& S. Zerafa (Eds.), Challenges and Opportunities of Sustainable Economic Growth: The Case of Malta (pp. 15-29). Valletta: Central Bank of Malta.

National Statistics Office. (2018). Population Statistics (Revisions): 2012-2016. Press Release $022 / 2018$.

Office for National Statistics. (2016). National population projections accuracy report.

Rapa, N. (2017). The macroeconomic effects of efficiency gains in electricity production in Malta. Central Bank of Malta, Policy Note. 


\section{Notes}

Note 1. There are other sources of population projections for Malta, notably those made by the United Nations Population Division (see https://esa.un.org/unpd/wpp/).

Note 2. For a technical overview of the Europop-2015 projections, see Eurostat (2017).

Note 3. For more details please refer to Eurostat website below http://ec.europa.eu/eurostat/statisticsexplained/index.php/Migration_and_migrant_population_statistics\#Migration_flows

Note 4. The impacts presented in this section are defined as the annual average growth deviations related to the different periods. For example: an average of 0.1 percentage point deviation for the period 2016-2020 implies a cumulative impact of 0.5 percentage point.

Note 5. Note that EUROPOP-2015's high migrant scenario still implies a net migration assumption which would be approximately half the net migration observed since 2014 .

Note 6. Grech (2017), in fact, notes that after rising from 1.7\% of the total workforce in 2004 to $5 \%$ by 2008 , this share then remained unchanged till 2010 . The short economic downturn experienced in Malta was more sharply felt by foreign employees, as whereas the employment of Maltese citizens continued relatively unabated, the employment of foreigners fell by $7 \%$, mostly among third-country nationals.

\section{Copyright Disclaimer}

Copyright for this article is retained by the author(s), with first publication rights granted to the journal.

This is an open-access article distributed under the terms and conditions of the Creative Commons Attribution license (http://creativecommons.org/licenses/by/3.0/). 